\title{
Pharmacological Rescue of Cortical Synaptic and Network Potentiation in a Mouse Model for Fragile X Syndrome
}

\author{
Tao Chen ${ }^{1,2}$, Jing-Shan Lu', Qian Song', Ming-Gang Liu' ${ }^{1,3}$, Kohei Koga ${ }^{1,3}$, Giannina Descalzi ${ }^{3}$, \\ Yun-Qing Li*,2 and Min Zhuo*,1,3 \\ 'Center for Neuron and Disease, Frontier Institute of Science and Technology, Xi'an Jiaotong University, Xi'an, China; '²Department of Anatomy \\ and KK Leung Brain Research Center, Fourth Military Medical University, Xi'an, China; ${ }^{3}$ Department of Physiology, Faculty of Medicine, \\ University of Toronto, Toronto, ON, Canada
}

\begin{abstract}
Fragile $X$ syndrome, caused by the mutation of the Fmrl gene, is characterized by deficits of attention and learning ability. In the hippocampus of Fmrl knockout mice (KO), long-term depression is enhanced whereas long-term potentiation (LTP) including late-phase LTP (L-LTP) is reduced or unaffected. Here we examined L-LTP in the anterior cingulate cortex (ACC) in Fmrl KO mice by using a 64electrode array recording system. In wild-type mice, theta-burst stimulation induced L-LTP that does not occur in all active electrodes/ channels within the cingulate circuit and is typically detected in $\sim 75 \%$ of active channels. Furthermore, L-LTP recruited new responses from previous inactive channels. Both L-LTP and the recruitment of inactive responses were blocked in the ACC slices of Fmr I KO mice. Bath application of metabotropic glutamate receptor 5 (mGluR5) antagonist or glycogen synthase kinase-3 (GSK3) inhibitors rescued the L-LTP and network recruitment. Our results demonstrate that loss of FMRP will greatly impair L-LTP and recruitment of cortical network in the ACC that can be rescued by pharmacological inhibition of mGluR5 or GSK3. This study is the first report of the network properties of L-LTP in the ACC, and provides basic mechanisms for future treatment of cortex-related cognitive defects in fragile $X$ patients. Neuropsychopharmacology (2014) 39, 1955-1967; doi:I0.1038/npp.2014.44; published online I2 March 2014
\end{abstract}

\section{INTRODUCTION}

Fragile X syndrome (FXS), one of the most common inherited causes of autism, is characterized by moderate to severe deficits of attention and learning ability (Bhakar et al, 2012). It originates from the loss of fragile X mental retardation protein (FMRP) because of a mutation of the Fmr1 gene (Bagni and Greenough, 2005; Bear et al, 2004; O'Donnell and Warren, 2002). As FMRP is confirmed to be a repressor of synaptic protein synthesis (Bear et al, 2004; Bhakar et al, 2012), loss of FMRP in FXS may lead to deficits in synaptic plasticity and information storage. Indeed, it has been reported that FMRP can negatively regulate proteins that trigger AMPA receptor internalization (Park et al, 2008; Waung et al, 2008), and Fmrl knockout (KO) mice display exaggerated long-term depression in the hippocampus (Huber et al, 2002; Zhang et al, 2009) and cerebellum (Koekkoek et al, 2005).

Long-term potentiation (LTP) is a well-studied phenomenon shown to mediate synaptic transmission, and is

\footnotetext{
* Correspondence: Dr YQ Li, Department of Anatomy and KK Leung Brain Research Center, Fourth Military Medical University, Xi'an 7l0032, China, Tel: +86 29 8477450 I, Fax: +86 29 83283229, E-mail: deptanat@fmmu.edu.cn or Dr M Zhuo, Department of Physiology, Faculty of Medicine, University of Toronto, I King's College Circle, Toronto, ON M5S IA8, Canada, Tel: +I 416978 4018, Fax: + 416978 7398, E-mail: minzhuol0@gmail.com

Received 15 October 2013; revised 21 January 2014; accepted 4 February 2014; accepted article preview online 20 February 2014
}

considered to be the cellular model for learning and memory (Bliss et al, 2003; Bliss and Cooke, 2011; Kandel, 2001, 2009; Neves et al, 2008). LTP has at least two distinct phases: early-phase LTP (E-LTP), which does not need new protein synthesis or transcription, and late-phase LTP (LLTP), which is transcription and translation related (Abel et al, 1997; Frey et al, 1993; Kandel, 2001, 2009). To date, most LTP studies have been focusing on the hippocampus of Fmr1 KO mice. In the hippocampus, some studies show that LTP is intact (Auerbach and Bear, 2010; Bear et al, 2004; Godfraind et al, 1996; Paradee et al, 1999), whereas others confirm the deficit of LTP by using different LTP induction protocols (Hu et al, 2008; Lauterborn et al, 2007; Lee et al, 2011; Shang et al, 2009). Furthermore, L-LTP of the hippocampus was found to be normal in Fmr1 KO mice (Zhang et al, 2009). In the anterior cingulate cortex (ACC), we found that E-LTP induced by theta-burst stimulation (TBS) or the pairing training was impaired in Fmrl KO mice (Zhao et al, 2005a). Similar findings have been made in other regions of the cortex (Li et al, 2002; Meredith et al, 2007; Wilson and Cox, 2007; Zhao et al, 2005a). However, little is known about the roles of FMRP in cortical L-LTP.

Typical studies of L-LTP have been carried out using a single field recording electrode in brain slices, and there is no way to detect whether L-LTP also triggers synaptic changes in adjacent cortical network. In the present study, to investigate possible contributions of FMRP to L-LTP at both synaptic and network levels, we used a 64-channel multielectrode array recording system (MED64) to record 
L-LTP in the ACC of adult Fmr1 KO and wild-type (WT) mice. In the MED64 system, stable long-term field potentials can be recorded at multiple channels of the same ACC slices (Kang et al, 2012). It provides the unique method to study L-LTP within the local circuit of ACC. Both metabotropic glutamate receptor 5 (mGluR5) and glycogen synthase kinase-3 (GSK3) have been reported to be overexpressed in cortex in Fmr1 KO mice. Previous studies also find that inhibition of mGluR5 and GSK3 can rescue the impaired hippocampus-related learning ability in Fmr1 KO mice (Bhakar et al, 2012; Guo et al, 2012), we thus want to know whether inhibition of the mGluR5 and GSK3 has regulation effect on the long-term network plasticity in the ACC of Fmr1 KO mice.

\section{MATERIALS AND METHODS}

\section{Animals}

The animals used were adult (8-10 weeks old) male Fmr1 WT and KO mice (the breeding pairs were generously provided by Dr WT Greenough (University of Illinois, IL)). All mice were housed under a $12 \mathrm{~h}$ light/dark cycle with food and water provided ad libitum. The Animal Care and Use Committee of University of Toronto and Xi'an Jiaotong University approved all mouse protocols.

\section{Preparation of the Multielectrode Array}

The MED64 probe (P515A, Panasonic, Japan) has an array of 64 planar microelectrodes, arranged in an $8 \times 8$ pattern, with an interpolar distance of $150 \mu \mathrm{m}$. Before use, the surface of the MED64 probe was treated with $0.1 \%$ polyethyleneimine (Sigma, St Louis, MO; P-3143) in $25 \mathrm{mmol} / \mathrm{l}$ borate buffer ( $\mathrm{pH}$ 8.4 ) overnight at room temperature. Then, the probe surface was rinsed three times with sterile distilled water (Kang et al, 2012; Liu et al, 2013).

\section{Slice Preparation}

Coronal brain slices $(300 \mu \mathrm{m})$ from Fmr1 WT or KO mice, containing the ACC, were prepared using standard methods (Kang et al, 2012). After cutting, slices were then incubated in a submerged recovery chamber with oxygenated $\left(95 \% \mathrm{O}_{2}\right.$ and $5 \% \mathrm{CO}_{2}$ ) artificial cerebrospinal fluid (ACSF) containing (in $\mathrm{mM}$ ) $124 \mathrm{NaCl}, 4.4 \mathrm{KCl}, 2 \mathrm{CaCl}_{2}, 1 \mathrm{MgSO} 4,25$ $\mathrm{NaHCO}_{3}, 1 \mathrm{NaH}_{2} \mathrm{PO}_{4}$, and 10 glucose at room temperature for at least $1.5 \mathrm{~h}$.

\section{Electrophysiological Recordings}

After incubation, one slice was transferred to the recording chamber and subfused with ACSF at $28-30{ }^{\circ} \mathrm{C}$ and maintained at a $2 \mathrm{ml} / \mathrm{min}$ flow rate. The slices were positioned on the MED64 probe in such a way that the whole array of the electrodes can cover the different layers of the ACC, with middle part of the probe close to the central point of the ACC. One of the channels located in the layer V of the ACC, from which the best synaptic responses can be induced in the surrounding recording channels, was then chosen as the stimulation site. A microphotograph of one ACC slice positioned on the MED64 probe is shown in Figure 1a.
Slices were kept in the recording chamber for at least $1 \mathrm{~h}$ before the start of experiments. Bipolar constant current pulse stimulation $(1-10 \mu \mathrm{A}, 0.2 \mathrm{~ms})$ was applied to the stimulation channel and the intensity was adjusted so that a half-maximal field excitatory postsynaptic potential (fEPSP) was elicited in the channels closest to the stimulation site. The channels with fEPSP were considered as active channels and their fEPSP responses were sampled every $1 \mathrm{~min}$ and averaged every $4 \mathrm{~min}$. The parameter of 'slope' indicated the averaged slope of each fEPSP recorded by activated channels. Stable baseline responses were first recorded until the baseline response variation is $5 \%$ in most of the active channels within $1 \mathrm{~h}$. Then, a TBS (five trains of bursts with four pulses at $100 \mathrm{~Hz}$ at $200 \mathrm{~ms}$ interval; repeated five times at intervals of $10 \mathrm{~s}$ ) was applied to the same stimulation channel to induce L-LTP. Channels with baseline responses variation of $>5 \%$ were discarded. Normally, the number of channels with unstable baseline responses was $\leqslant 10 \%$ of the total number of active channels, according to the stable recording system (see Discussion section for the technical advantages of the Med64 system). If the number of unstable channels was $>10 \%$, the slice would be discarded.

\section{Cannulation and Microinjection}

Briefly, mice were anesthetized by an intraperitoneal injection of a mixture of ketamine $(0.16 \mathrm{mg} / \mathrm{kg})$ and xylazine $(0.01 \mathrm{mg} / \mathrm{kg})$. The scalp was shaved and then cleaned with povidone-iodine and alcohol. The head of the mouse was fixed into an adapter mounted on a stereotaxic frame and lubricant (artificial tears) was applied to the eyes. An incision was made over the skull and the surface was exposed. Two small holes were drilled above the ACC and the dura was gently reflected. Guide cannulas were placed so that the final coordinates for microinjection would be $0.7 \mathrm{~mm}$ anterior to the bregma, $0.3 \mathrm{~mm}$ lateral to the midline, and $1.75 \mathrm{~mm}$ ventral to the surface of the skull for the ACC, according to the atlas of Paxinos and Franklin (2001). For microinjection, the mice were restrained in a plastic cone (Braintree Scientific, MA), and a small hole over the guide cannulas was made. A 30-gauge injector $0.7 \mathrm{~mm}$ lower than the guide was used. Microinjection was conducted using a motorized syringe pump (Razel Scientific Instruments, CT) and a Hamilton microsyringe (Hamilton, Reno, NY). Normal saline, MPEP, or GSK inhibitor (SB415286 and CT99021) dissolved in saline were delivered bilaterally into the ACC $(0.5 \mu \mathrm{l} /$ side $)$. The volume delivered was confirmed by observing the downward movement of the meniscus in a calibrated polyethylene (PE10) tubing. The injector was left in place for $1 \mathrm{~min}$ to help prevent any solution from flowing back up the guide. After microinjection, the animals were immediately placed into a clear plastic cylinder for behavioral observation.

\section{Trace Fear Conditioning}

All conditioning was completed in an isolated shock chamber (Medical Associates, St Albans, VT) 1 week after cannula surgery. Trace fear conditioning was performed as reported previously (Wu et al, 2008; Zhao et al, 2005a). Briefly, the conditioned stimulus (CS) used was an $80-\mathrm{db}$ white noise, delivered for $15 \mathrm{~s}$, and the unconditioned stimulus (US) was a 

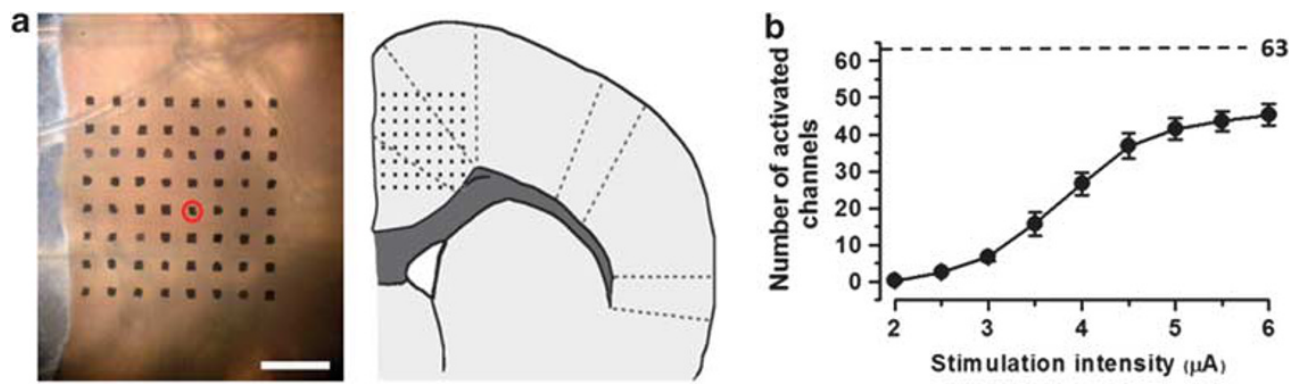

C
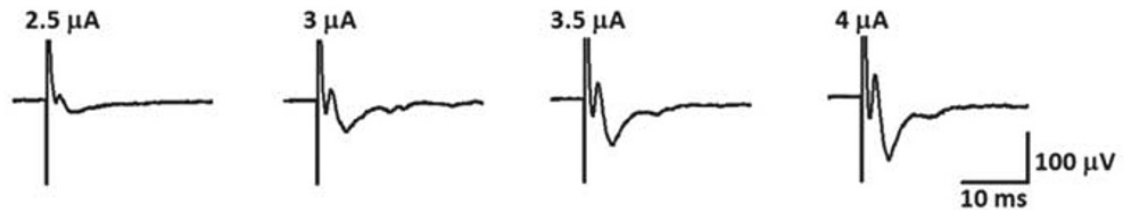

d

Baseline

e
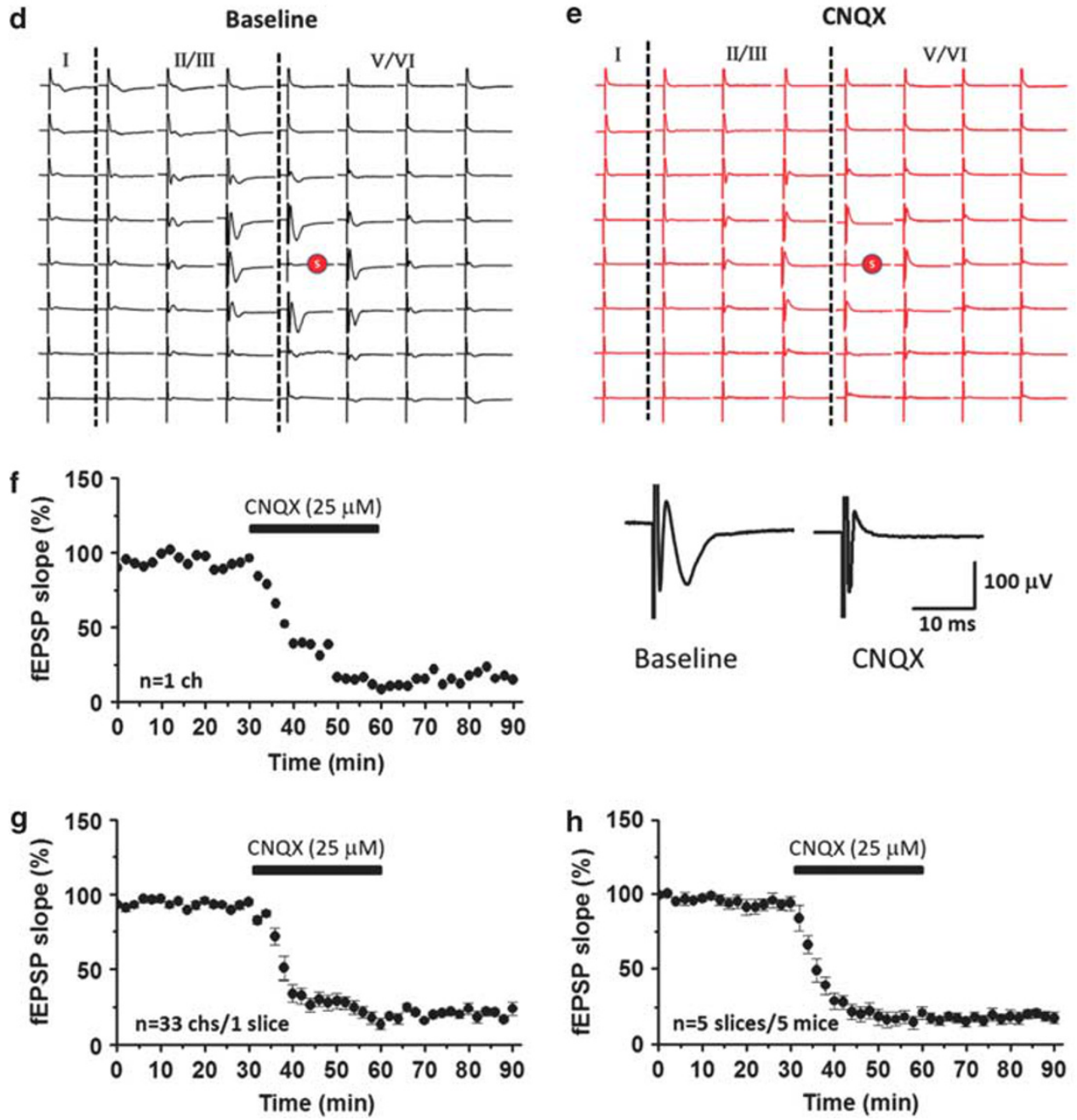

Figure I Network properties of the evoked fEPSPs in the ACC. (a) Microphotograph and schematic diagram showed one example for ACC fEPSP recording by using the MED64 system. A cortex slice containing the ACC was placed on a probe with 64 electrodes (MED-P5I5A, $8 \times 8$ array). One channel of the probe (red circle) was selected as the stimulation site. The evoked field potentials in all the other 63 channels were recorded I $\mathrm{h}$ before and $3 \mathrm{~h}$ after theta-burst stimulation (TBS). (b, c) The number of activated channels induced by different stimulation intensities (input-output) in Fmr I WT mice is shown in (b). Sample traces in (c) show one channel with enhanced fEPSP in response to different intensities of stimuli in Fmrl WT mice. (d, e) Two mapped figures showing that the evoked baseline potentials from all channels (d) were blocked by bath application of CNQX ( $25 \mu M$ ) (e). The red $\mathrm{S}$ indicates the stimulation site. ( $f$ ) The fEPSP slope (left) and the superimposed samples (right) from one channel show that CNQX blocked the potential. ( $\mathrm{g}$ ) The summarized fEPSP slopes show that CNQX blocked potentials from all 33 activated channels in one slice. (h) The summarized fEPSP slopes show that CNQX blocked all activated potentials from five slices in five mice. 
0.75-mA electric foot shock for $0.5 \mathrm{~s}$. At $30 \mathrm{~min}$ after saline, MPEP, SB415286, or CT99021 microinjection into the ACC, mice were placed into the chamber and acclimated for $5 \mathrm{~min}$, and were presented with 10 trials in the following order: CStrace-US-intertrial interval (ITI) (trace period $=30 \mathrm{~s}$, $\mathrm{ITI}=210 \mathrm{~s}$ ). In control group, WT or KO mice were only exposed to CS but not US. For memory retrieval tests, mice were introduced to a novel chamber and were acclimated for $5 \mathrm{~min}$ and subjected to a presentation of the CS to test for trace fear memory. All data were recorded using the videobased Freeze Frame fear conditioning system and analyzed by Actimetrics Software (Coulbourn Instruments, Wilmette). Freezing bouts of $\geqslant 1 \mathrm{~s}$ were considered as freezing (the absence of movement aside from respiration).

\section{Membrane Preparation}

Membrane preparation was performed as previously described (Descalzi et al, 2012). Briefly, ACC samples were dissected in cold D-PBS and resuspended in buffer $1(2 \mathrm{mM}$ Tris-EDTA, $320 \mathrm{mM}$ sucrose, $5 \mathrm{mM} \mathrm{MgCl}_{2}$, and $1 \times$ protease inhibitor cocktail, $\mathrm{pH}$ 7.4), and homogenized. Each sample was centrifuged at $1000 \mathrm{~g}$ for $10 \mathrm{~min}$ and the supernatants (S1) were recovered. The remaining pellet (P1) was then resuspended in buffer $2(50 \mathrm{mM}$ Tris- $\mathrm{HCl}, 2 \mathrm{mM}$ Tris-EDTA, $5 \mathrm{mM} \mathrm{MgCl}$, and $1 \times$ phosphatase inhibitor cocktails 1 and 2, pH 7.0) and centrifuged at $1000 \mathrm{~g}$ for $10 \mathrm{~min}$, with its supernatant (S2) collected and combined with $\mathrm{S} 1$. The remaining pellet (P2) was resuspended in buffer 2, and again centrifuged at $1000 \mathrm{~g}$ for $10 \mathrm{~min}$, and its supernatant (S3) was combined with S1 and S2. Combined supernatant fractions (S1, S2, and S3) were finally centrifuged at $39000 \mathrm{~g}$ for $30 \mathrm{~min}$, the resulting supernatant contained the cytosolic fractions, and the resulting pellet (membrane fractions) was resuspended in buffer $3(50 \mathrm{mM}$ Tris- $\mathrm{HCl}, 2 \mathrm{mM}$ Tris-EDTA, $3 \mathrm{mM} \mathrm{MgCl}_{2}$, and $1 \times$ phosphatase inhibitor cocktails 1 and 2, pH 7.4).

\section{Western Blot}

Western blot was performed as previously described (Wang et al, 2007). Sample protein concentrations were quantified using Bradford assay, and electrophoresis of equal amounts of protein was performed on SDS-polyacrylamide gel. Separated proteins were transferred to polyvinylidene fluoride membranes for analysis, and were then probed with primary antibodies as follows: anti-GluA1 (1:3000, rabbit polyclonal, Millipore), anti- $\beta$-actin $(1: 2000$, rabbit polyclonal, Sigma), followed by horseradish peroxidasecoupled secondary antibody diluted at $1: 5000$ for $1 \mathrm{~h}$ followed by enhanced chemiluminescence detection of the proteins with Western lightning chemiluminescence reagent plus (PerkinElmer Life Sciences). ImageJ software (National Institute of Health) was used to assess the density of immunoblots by a blind observer.

\section{Data Analysis}

Student's $t$-test (for comparisons between two groups), oneway repeated measures ANOVA and two-way ANOVA followed by Holm-Sidak test (for comparison of multiple groups with one control group), or the Student-Newman-
Keuls test (SNK test, for comparisons among multiple groups) were used for measurement data analysis. The $\chi^{2}$ test was used for enumeration data analysis. In all cases, $p<0.05$ is considered statistically significant.

\section{RESULTS}

\section{Recording of Baseline Field Potentials using MED64 in the ACC}

In previous studies, by using dual whole-cell patch clamp recording methods, we found that neurons in the ACC are highly wired within layers I-III (Wu et al, 2009). To characterize the intercellular connections, we used the 64 electrodes/channels recording system to map cortical circuit responses within the whole ACC in response to focal electrical stimulation. As shown in Figure 1a, one channel in the deeper layer of the ACC (layer V) was chosen as the stimulation site, and the other 63 channels were used for measuring evoked responses. We found that local stimulation induced widespread fEPSPs within the ACC. The number of channels where fEPSPs were detected increased with greater intensities of stimulation. Within the 63 recorded channels, the maximal number of activated channels was $45.3 \pm 2.9$ channels $(n=6$ slices/6 mice; Figure $1 \mathrm{~b}$ and $\mathrm{c})$. After bath application of the AMPA/ kainate receptor antagonist CNQX $(25 \mu \mathrm{M})$, the fEPSPs were completed abolished, indicating that the fEPSPs were mediated by glutamate AMPA/kainate receptors $(n=5$ slices/5 mice; Figure 1d-h). AMPA receptor antagonist GYKI 53655 was also tested. Bath application of GYKI53655 $(100 \mu \mathrm{M})$ blocked fEPSPs (see Supplementary Figure 1), suggesting that the evoked field responses are mainly mediated by AMPA receptor.

\section{L-LTP within ACC Local Networks of FMRP WT Mice}

We then applied TBS to determine whether we could record L-LTP from ACC slices using the MED64 system. After applying TBS (five trains of burst with four pulses at $100 \mathrm{~Hz}$ at $200 \mathrm{~ms}$ interval; repeated five times at intervals of $10 \mathrm{~s}$ ), we found that most of the fEPSPs were significantly enhanced, and that the enhancement lasted for at least $3 \mathrm{~h}$ (Figure $2 \mathrm{a}$ and $\mathrm{c}$ ). This allowed us to address an interesting question by the 64-channel array system: does LTP induction only affect individual channels or all active channels? Our results showed that not all responses underwent L-LTP after TBS induction. For example, in one typical sample slice with 25 active responses, only 17 showed potentiation of the fEPSP slope lasting for $3 \mathrm{~h}$ (153.8 $\pm 5.0 \%$ of baseline, $n=17$ ), 3 of them only showed short-term (normally decayed after $1.5 \mathrm{~h}$ ) potentiation, and 5 of them remained stable throughout the entire recording period (Figure $2 \mathrm{a}$ and $\mathrm{c}-\mathrm{e}$ ). The final averaged slope for all 25 channels was $136.3 \pm 6.4 \%$ of the baseline at $3 \mathrm{~h}$ after TBS induction (Figure $2 \mathrm{f}$ ). In total, we performed recordings on seven slices from seven mice. In total, from the 143 active channels from which fEPSP could be recorded, 107 channels $(75.0 \%)$ showed clear L-LTP that lasted for $3 \mathrm{~h}$, 15 channels $(10.5 \%)$ showed short-term potentiation, and 21 channels $(14.7 \%)$ showed no potentiation. The mean potentiation for 107 channels with L-LTP reached 
a
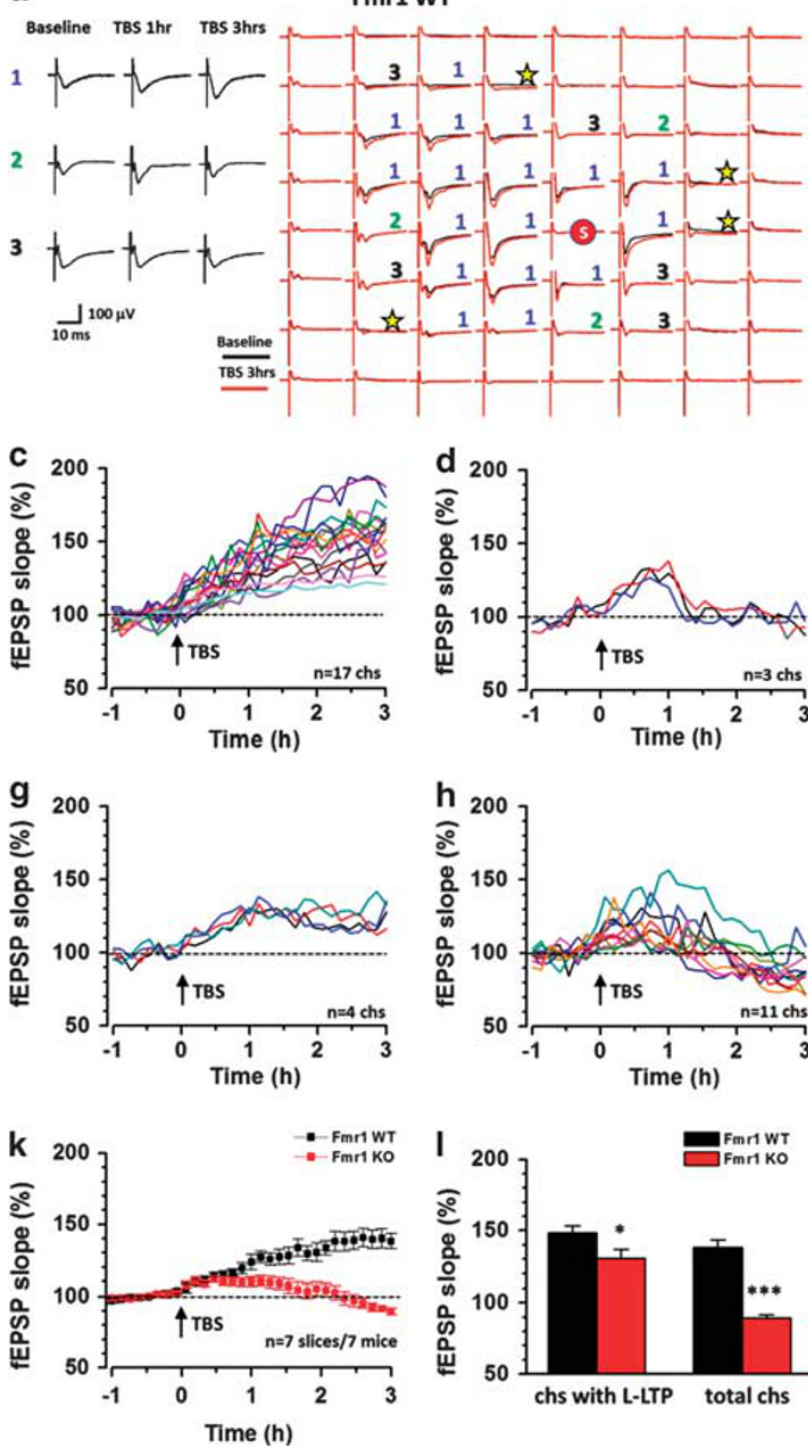

b
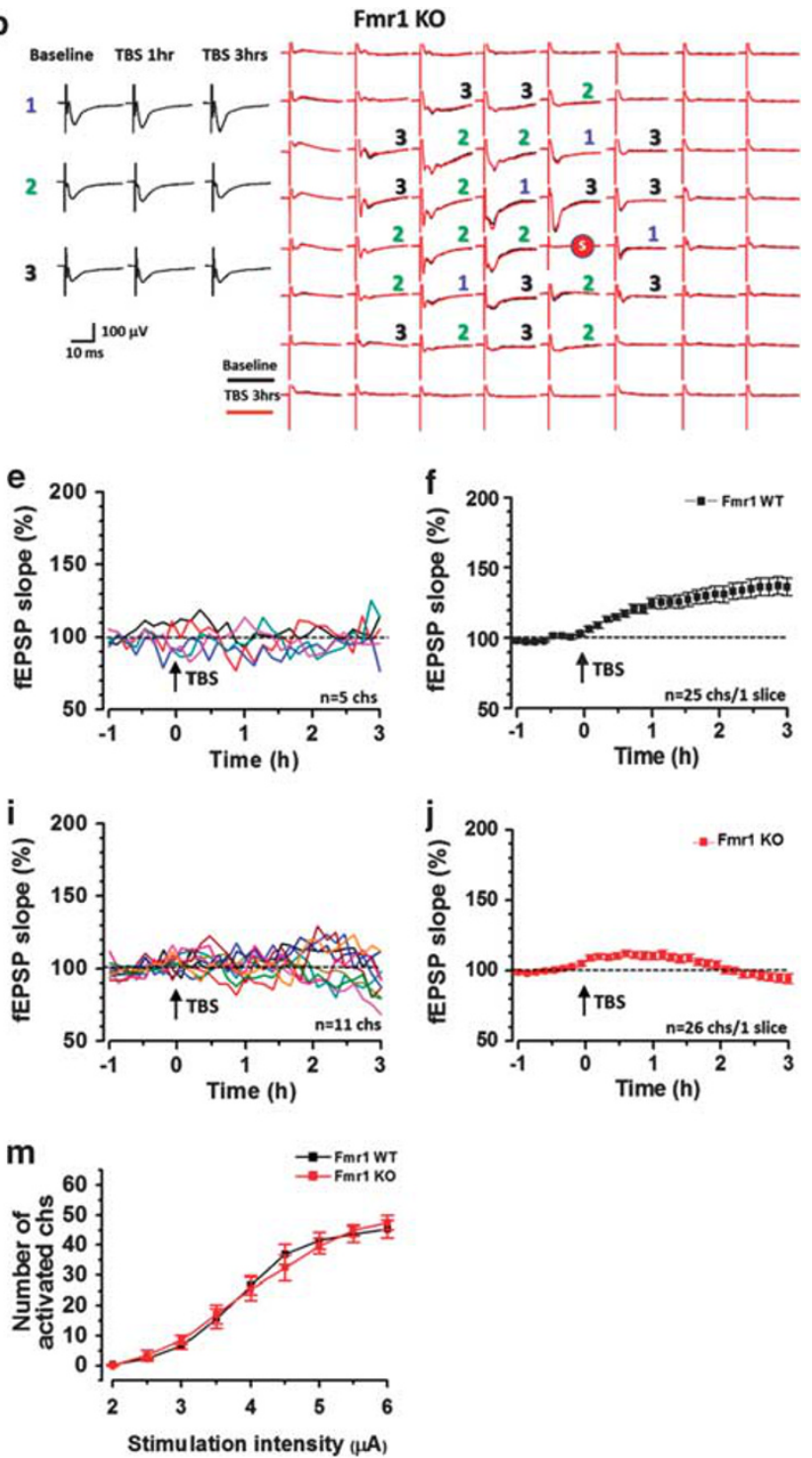

Figure 2 Network plasticity of the fEPSPs after L-LTP induction in the ACC of Fmr I WT and KO mice. (a, b) Two mapped figures show the evoked field potentials in the ACC of Fmr I WT (a) and KO (b) mice. Field potentials were recorded from the other 63 channels $0.5 \mathrm{~h}$ before (black) and $3 \mathrm{~h}$ (red) after TBS being delivered to one channel marked as 's'. Asterisks from the mapped figure of Fmrl WT mouse indicate the channels with recruited fEPSPs. Superimposed sample traces at different time points (baseline and I and $3 \mathrm{~h}$ after TBS) show three types of plasticity: channels showing typical L-LTP are marked as (I), in which gradually increased slope of the fEPSP could be detected after TBS and lasted for 3 h; channels showing relative short-term potentiation after TBS (decline within 1.5 h) are marked as (2); channels without change in the slope of the fEPSP are marked as (3). The fEPSP slope of I7 channels with L-LTP (c), 3 channels with short-term potentiation (d), and 5 channels without potentiation (e) from I slice of I Fmr I WT mouse is shown, respectively. The averaged slope of the total 25 channels is shown in (f). The fEPSP slope of 4 channels with L-LTP (g), II channels with short-term potentiation (h), and II channels without potentiation (i) from I slice of I Fmr I KO mouse is shown, respectively. The averaged slope of the total 26 channels is shown in (j). ( $k$ ) Time course of the averaged fEPSP slope of all recorded channels in Fmrl WT and KO mice (seven slices/seven mice in each group). (I) The averaged slope of fEPSPs from channels with L-LTP and from total active channels of Fmrl WT and KO mice. * $p<0.05$, **** $p<0.00 \mathrm{I}$. (m) The number of activated channels induced by different stimulation intensities (input-output) in Fmr I KO mice and WT mice.

$148.4 \pm 4.8 \%$ of the baseline at $3 \mathrm{~h}$ after TBS. The overall mean potentiation of all 143 channels is $139.3 \pm 6.3 \%(n=7$ slices/7 mice; Figure 2k and 1).

New protein synthesis is known to be important for L-LTP in the hippocampus (see Kandel, 2001 for review). We then applied protein synthesis inhibitor anisomycin (Barco et al, 2002; Toyoda et al, 2010) to check whether the L-LTP could be affected. In the presence of $25 \mu \mathrm{M}$ anisomycin, the number of channels showing L-LTP was significantly reduced (Figure 3 ). In one typical slice with 27 active channels, only 5 channels showed L-LTP. Instead, 14 channels showed short-term potentiation and 8 channels showed no potentiation (Figure 3a-e). In a total of 139 channels recorded on 6 slices from 5 mice, 26 (18.7\%), 74 (53.2\%), and $39(28.1 \%)$ channels showed L-LTP, shortterm potentiation, and no potentiation, respectively. The mean potentiation for all 139 channels was $102.0 \pm 3.7 \%$ of the baseline at $3 \mathrm{~h}$ after TBS (Figure 3f). Finally, NMDA receptors are known to be important for the induction of LTP in the ACC (Zhao et al, 2005b). To test whether NMDA 

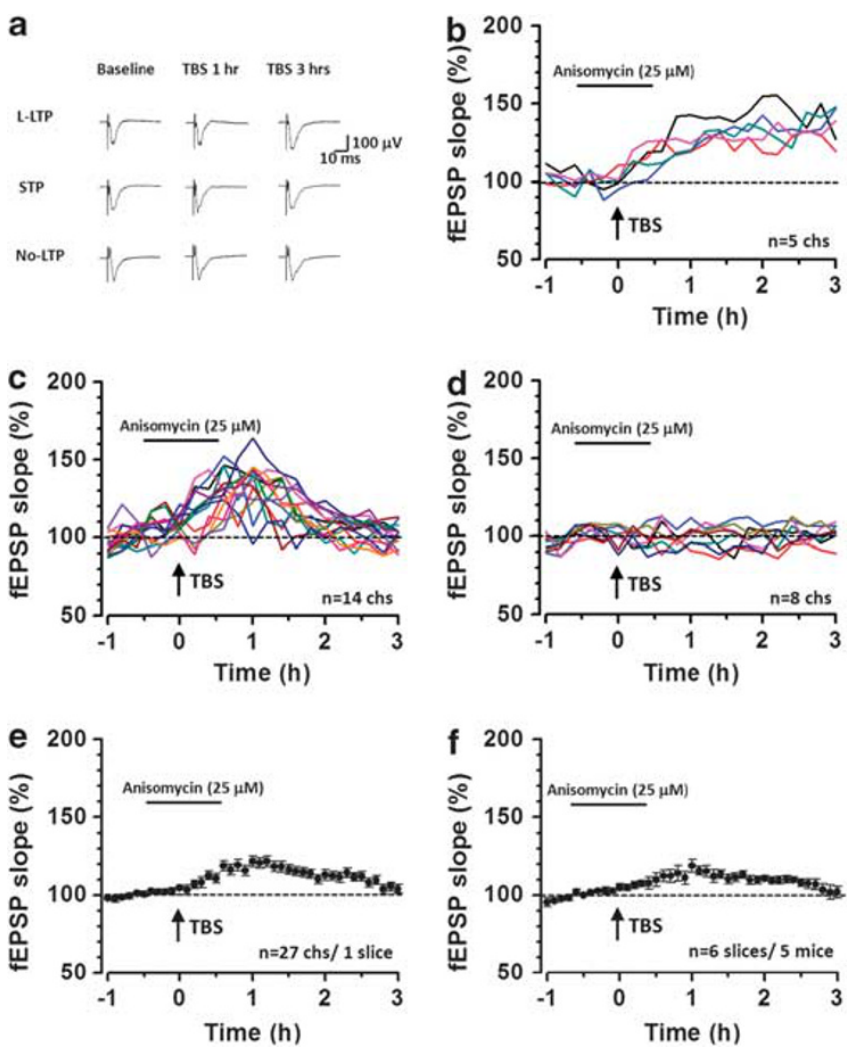

Figure 3 Long-term plasticity of the fEPSP is dependent on new protein synthesis. (a) The superimposed traces at different time points (baseline and $\mathrm{I}$ and $3 \mathrm{~h}$ after TBS) show channels with L-LTP, short-term potentiation (STP), and no potentiation of the fEPSP slope. The fEPSP slope of 5 channels with L-LTP (b), I 4 channels with STP (c), and 8 channels without potentiation (d) from I slice of I Fmr I WT mouse is shown separately. The averaged slope of the total 27 channels is shown in (e). The averaged slope from total six slices in five mice is shown in $(f)$.

receptors are required for the induction of cingulate network L-LTP, we applied the NMDA receptor antagonist AP5 $(100 \mu \mathrm{M})$ and found that L-LTP was completely blocked in all tested slices $(97.5 \pm 4.6 \%$ of the baseline at $1.5 \mathrm{~h}$ after TBS induction, $n=6$ slices/ 6 mice; Figure 4 ). These results are consistent with our previous work, indicating that the induction of ACC LTP is dependent on NMDA receptors (Liauw et al, 2005; Zhao et al, 2005b).

\section{Recruitment of Synaptic Responses within the ACC Network after LTP Induction}

One interesting finding from our L-LTP recordings in the ACC of Fmrl WT mice is that some channels $(3.9 \pm 0.6$, $n=27$ channels from total 7 slices $/ 7$ mice) that were inactive during baseline recordings showed evoked fEPSPs after TBS induction. These newly recruited channels were located on the edge of the originally active area (Figures $2 a, 5 a$, and $6 a$ ). After TBS induction, the average amplitude of fEPSPs of recruited channels gradually increased (finally reached as large as $17.1 \pm 1.3 \mu \mathrm{V}$ ) and remained stable for $3 \mathrm{~h}$ (Figure 5b-d). Such recruitment was evident in all recorded slices $(n=7$ slices/7 mice). Importantly, TBS-induced recruitment occurred only on some channels on the edge of the active area, whereas most of the edge channels remained inactive throughout the recording, indicating that the recruitment is unlikely because of alterations of stimulation intensities or unstable recordings.

\section{Requirement of FMRP for L-LTP and Network Recruitment}

We then examined the network properties of L-LTP in Fmr1 KO mice. After application of TBS, we found a significant deficit of L-LTP induction. In a typical slice with 26 active channels, the fEPSP slope with L-LTP lasting for $3 \mathrm{~h}$ could only be observed in 4 channels. Furthermore, the degree of potentiation from these channels is significantly smaller than that of WT mice. Short-term potentiation, which normally decayed after $1.5 \mathrm{~h}$, could be detected in 11 channels. The remaining 11 channels showed no potentiation, or decayed gradually after TBS induction (Figure $2 \mathrm{~b}$ and $\mathrm{g}-\mathrm{i}$ ). In sum, in a total of 138 recorded channels of 7 slices from 7 mice, only 24 channels $(17.4 \%)$ had L-LTP; less than half of the channels $(42.8 \%, 59$ channels) showed short-term potentiation. In the remaining channels $(39.8 \%$, 55 channels), fEPSPs could not be potentiated by TBS. The number of channels showing L-LTP in Fmr1 KO mice was significantly less than that in WT mice $\left(\chi^{2}=93.09, n=281\right.$, $p<0.001, \chi^{2}$ test; channels with L-LTP were considered as positive whereas channels without L-LTP were considered as negative). In addition, the averaged potentiation of the 24 channels with L-LTP was $130.3 \pm 6.6 \%$ of baseline at $3 \mathrm{~h}$ after the induction, whereas that of all 138 channels was $89.4 \pm 2.3 \%$ of the baseline at $3 \mathrm{~h}$ after TBS. They were significantly smaller than those in Fmr1 WT mice ( $p=0.042$ compared with $148.4 \pm 4.8 \%$ of the baseline in 107 channels with L-LTP in Fmr1 WT mice; $p<0.001$ compared with $139.3 \pm 6.3 \%$ of the baseline in all 143 channels in Fmr1 WT mice, $n=7$ slices $/ 7$ mice in each group, unpaired $t$-test; Figure $2 \mathrm{~g}-1$ ). Furthermore, we did not find any obvious recruitment of fEPSPs on any of the recorded slices from Fmr1 KO mice ( $n=7$ slices/7 mice). Finally, there is no difference in the input-output curve in the ACC slices of Fmr1 KO and WT mice $\left(\mathrm{F}_{(1,90)}=0.0002, p=0.98 ; n=6\right.$ slices/6 mice in each group, two-way ANOVA; Figure 2m), suggesting that the basal synaptic transmission is not changed in Fmr1 KO mice (Zhao et al, 2005a). In sum, the results suggest that FMRP is important for the LTP of the activated fEPSPs and the recruitment of synaptic responses, but not the basal synaptic transmission in the ACC.

\section{Pharmaceutical Rescuing of L-LTP and Network Recruitment in Fmr1 KO Mice}

FMRP functions as a repressor of translation and transport of many mRNAs in dendritic spines, and thus genetic deletion of FMRP will lead to the overexpression of synaptic protein synthesis that are important for synaptic plasticity (Bear et al, 2004; Bhakar et al, 2012; Huber et al, 2002). Among them, the exaggerated mGluR5 signaling is considered as the core mechanism for the pathological phenotype of FXS (Bear et al, 2004; Bhakar et al, 2012; Dolen and Bear, 2008). We thus tested whether mGluR5 antagonist MPEP could rescue the deficient L-LTP and network recruitment observed in ACC slices of Fmr1 KO 
a
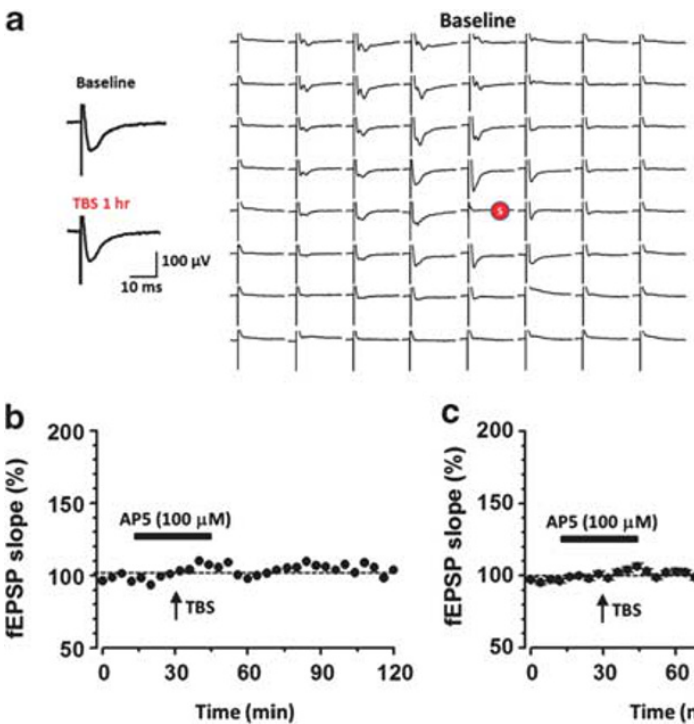

C

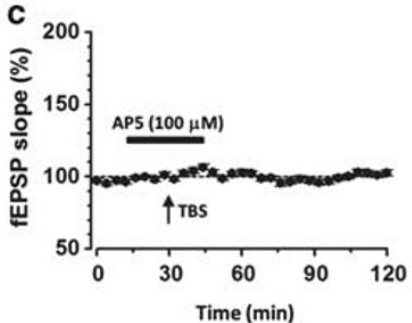

Figure 4 Network plasticity of the fEPSP depends on the NMDA receptor. (a) Two mapped figures and superimposed traces showing that AP5 $($ I $00 \mu \mathrm{M})$ application during TBS induction completely blocked the network LTP of the evoked potentials in the ACC. The red S indicates the stimulation site. (b) The fEPSP slope from I channel shows that AP5 blocked the LTP induced by TBS. (c) The summarized fEPSP slope shows that AP5 blocked the LTP from all activated channels in one slice. (d) The summarized fEPSP slope shows that AP5 blocked the LTP of all activated potentials from six slices from six mice (one slice per animal).
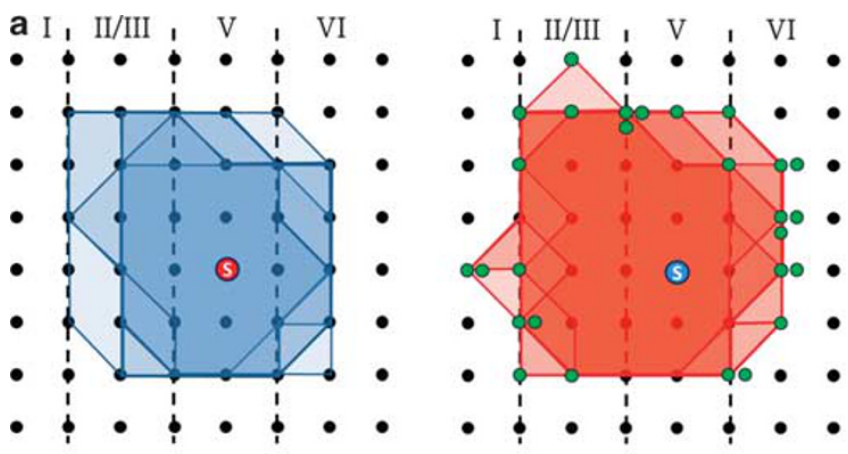

b
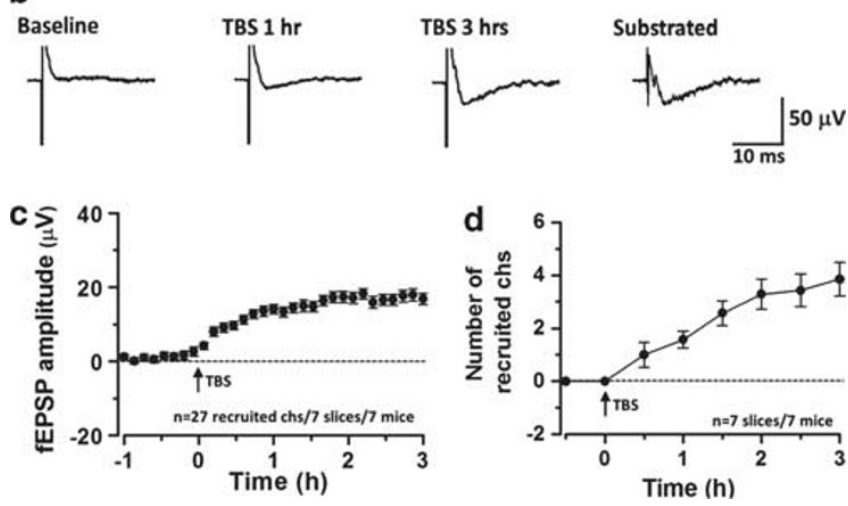

Figure 5 Recruitment of synaptic responses within the ACC after L-LTP induction. (a) The polygonal diagram shows the baseline area of the activated channels with fEPSP (blue) and the enlarged area after TBS (red). The circled $\mathrm{S}$ indicates the stimulation site. The recruited channels are shown as green dots. In some sites, more than one green dot is shown. It means the recruited fEPSPs could be observed in the same channel in different slices ( $n=7$ slices/7 mice). (b) The superimposed traces indicate one channel showing recruited fEPSPs after TBS. (c) The amplitude of fEPSPs is summarized from all recruited channels $(n=27$ channels from 7 slices/7 mice). (d) The number of recruited channels is summarized after TBS induction. mice. Furthermore, GSK3 functions closely to mGluR5 signaling, and excessive expression of GSK3 in cortex has been reported in Fmr1 KO mice (Berry-Kravis et al, 2008; Min et al, 2009). We also tested whether inhibition of GSK3 could rescue L-LTP and network recruitment. After bath application of MPEP $(1 \mu \mathrm{M})$ or GSK inhibitors (SB415286, $10 \mu \mathrm{M}$ or CT99021, $1 \mu \mathrm{M}$ ) for $1 \mathrm{~h}$ during the LTP induction period (given $30 \mathrm{~min}$ before TBS and washed out $30 \mathrm{~min}$ after TBS), we found that the baseline of the fEPSP in the ACC was not changed in both Fmr1 WT and KO mice ( $p>0.05$, unpaired $t$-test). However, the deficient L-LTP and network recruitment were rescued in Fmrl KO mice (Figure 6a). After MPEP application, 91 recorded channels (66.9\%, from a total of 136 active channels, 7 slices/6 mice) showed L-LTP that lasted for $3 \mathrm{~h}$, with the remaining channels showing only short-term or no potentiation of the fEPSPs. The mean potentiation for these 136 channels is $129.7 \pm 10.5 \%$ of the baseline at $3 \mathrm{~h}$ after TBS induction (Figure 6b and e). In comparison with Fmr1 WT mice with only ACSF application, the number of channels that showed L-LTP in Fmr1 KO mice with MPEP application was not different $\left(\chi^{2}=2.11, \quad n=279, \quad p=0.15, \quad \chi^{2}\right.$ test). After SB415286 bath application, 87 channels $(69.6 \%$, in total 125 active channels, 6 slice/ 6 mice) showed L-LTP that lasted for $3 \mathrm{~h}$. The final potentiation for these 125 channels is $134.5 \pm 6.5 \%$ of the baseline at $3 \mathrm{~h}$ after TBS (Figure $6 \mathrm{c}$ and e). Similarly, after bath application of CT99021, 89 channels (68.5\%, in total 130 active channels, 6 slice/6 mice) showed L-LTP that lasted for $3 \mathrm{~h}$. The mean potentiation for these 130 channels is $143.1 \pm 9.3 \%$ of the baseline at $3 \mathrm{~h}$ after TBS (Figure 6d and e). In comparison with Fmr1 WT mice, the number of channels that showed L-LTP in Fmr1 KO mice with GSK inhibitor application was not significantly different (SB415286: $\chi^{2}=0.91, n=268, p=0.34$; CT99021: $\chi^{2}=1.36, n=273, p=0.24, \chi^{2}$ test). Moreover, we found that inhibition of mGluR5 or GSK3 rescued the recruitment 
a

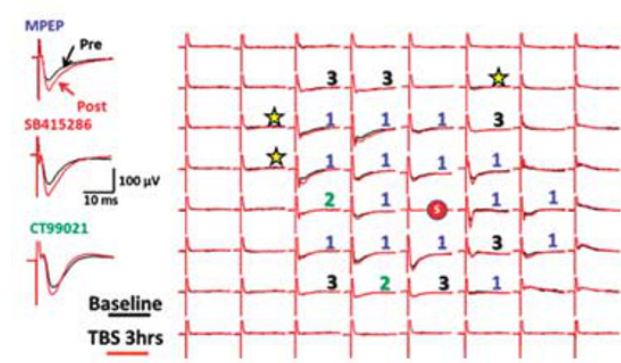

SB415286

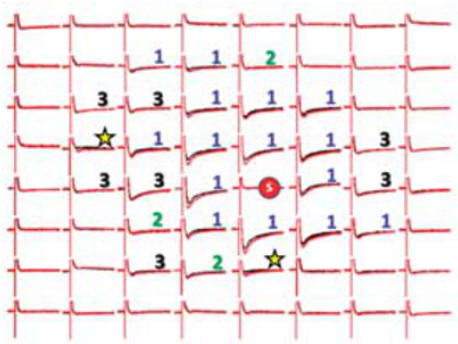

Ст99021

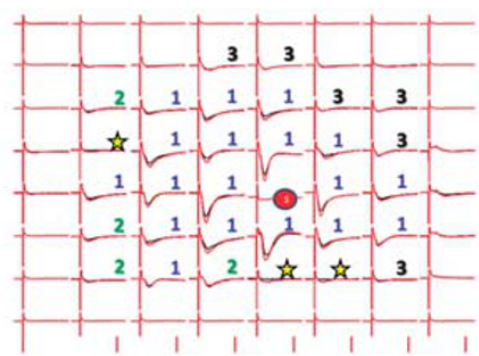

e
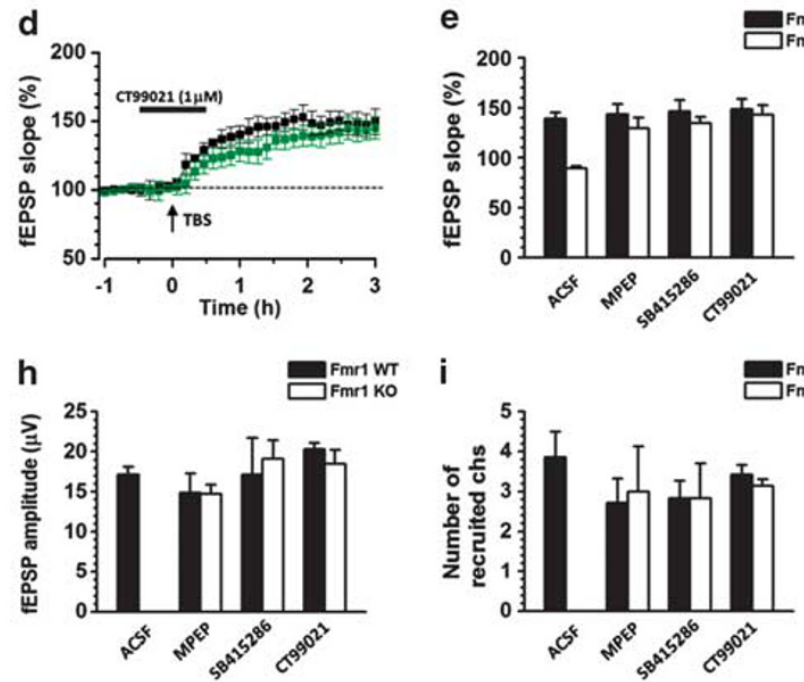

i

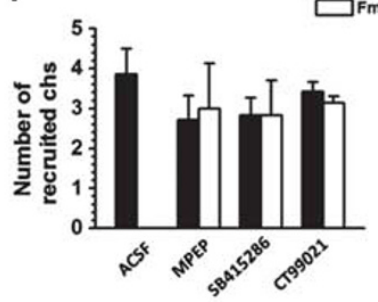

m

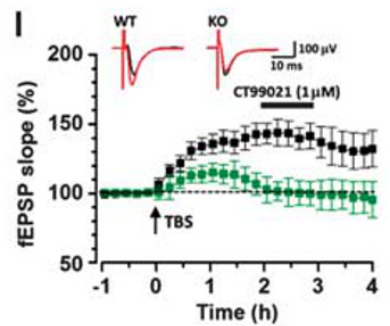

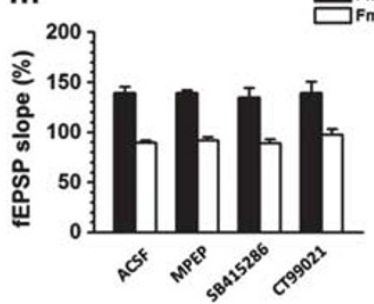

Figure 6 Inhibition of mGluR5 or GSK3 rescued the impaired L-LTP and recruitment of the synaptic responses in the ACC of Fmr I KO mice. (a) Three mapped figures show the rescued network L-LTP in the ACC slices of Fmr I KO mice with inhibition of mGluR5 by MPEP (I $\mu$ M) or GSK3 by SB 4 I5286 $(\mathrm{I} 0 \mu \mathrm{M})$ or CT9902 I (I $\mu \mathrm{M})$. The superimposed samples were taken at I h before (Pre, black) and $3 \mathrm{~h}$ after (Post, red) TBS. Asterisks indicate TBS-recruited synaptic responses. Channels with L-LTP (I), short- term potentiation (2), or without potentiation (3) of the EPSP slope are marked. (b-d) The averaged fEPSP slope shows that bath application (I h during TBS application) of MPEP (b, blue), SB4 I5286 (c, red), or CT9902I (d, green) rescued the L-LTP in the ACC slice of Fmrl KO mice. Meanwhile, MPEP (b, black), SB4I5286 (c, black), or CT9902I (d, black) application did not change the L-LTP properties in the ACC of Fmrl WT mice. The averaged slopes of fEPSPs from Fmrl WT and KO mice with ACSF, MPEP, SB4 I5286, or CT9902 I application at $3 \mathrm{~h}$ after TBS are plotted in (e). Application of MPEP, SB4 5286, and CT9902I rescued the recruitment of synaptic responses in Fmrl KO mice and the averaged amplitude and number of the recruited channels are shown in ( $f$ ) and (g). The amplitude and number of the recruited channels from Fmrl WT and KO mice with ACSF, MPEP, SB4 I5286, or CT9902I application at $3 \mathrm{~h}$ after TBS are plotted in (h) and (i). (j-I) MPEP, SB4I 5286, or CT9902I application during the maintenance phase of the L-LTP had no effect on the fEPSP of Fmrl WT and KO mice. The summarized fEPSP slope I h after ACSF or drug application is plotted in (m).

of the synaptic responses. After bath application of MPEP, SB415286, or CT99021, $3.0 \pm 1.1$ ( $n=7$ slices), $2.8 \pm 0.9$ ( $n=6$ slices), or $3.1 \pm 0.2$ ( $n=6$ slices) channels, respectively, showed recruited fEPSPs, with the averaged amplitude reaching $14.7 \pm 1.2 \mu \mathrm{V}$ ( $n=18$ channels), $19.1 \pm 2.3 \mu \mathrm{V}$ ( $n=16$ channels $)$, or $18.5 \pm 1.8 \mu \mathrm{V}(n=16$ channels $)$ at $3 \mathrm{~h}$ after TBS induction (Figure $6 \mathrm{f}-\mathrm{i}$ ). There was no statistically significant difference among the groups of Fmrl WT + ACSF, KO + MPEP, KO + SB415286, and KO + CT99021 in the number of active channels $\left(\mathrm{F}_{(3,16)}=0.06, p=0.98\right)$, the mean potentiation of active channels $\left(\mathrm{F}_{(3,16)}=0.50\right.$, $p=0.69)$, amplitudes of recruited fEPSPs $\left(\mathrm{F}_{(3,16)}=2.15\right.$, $p=0.13)$, and number of recruited channels $\left(\mathrm{F}_{(3,16)}=0.55\right.$, $p=0.66$ ) at $3 \mathrm{~h}$ after TBS induction (one-way repeated measures ANOVA). Finally, bath application of MPEP or GSK inhibitors during the LTP induction phase did not change the LTP properties of the WT mice (WT + ACSF: $139.3 \pm 5.3 \%$ of the baseline, $n=7$ slices/7 mice; WT + MPEP: $143.8 \pm 9.9 \%, n=7$ slices $/ 7$ mice; $\mathrm{WT}+\mathrm{SB} 415286$ : $146.3 \pm 11.6 \%, n=6$ slices/ 6 mice; WT + CT99021: $148.8 \pm$ 
$10.3 \%, n=6$ slices $/ 6$ mice; $\mathrm{F}_{(3,16)}=1.08, p=0.39$, one-way repeated measures ANOVA; Figure 6b-e).

We then tested whether inhibition of mGluR5 or GSK during the maintenance of the LTP could affect the L-LTP in Fmr1 WT and KO mice. MPEP $(1 \mu \mathrm{M})$, SB415286 $(10 \mu \mathrm{M})$, or CT99021 $(1 \mu \mathrm{M})$ were thus bath applied $2 \mathrm{~h}$ after TBS induction and washed out $1 \mathrm{~h}$ later. Results showed that, different from the effect when drugs were applied during the induction phase in Fmr1 KO mice, bath application of MPEP, SB415286, or CT99021 during LTP maintenance phase could not rescue the impaired L-LTP in Fmr1 KO mice (MPEP: 92.1 $\pm 3.2 \%$, SB415286: $89.1 \pm 3.8 \%$, CT99021: $97.3 \pm 6.0 \%$ of the baseline at $3 \mathrm{~h}$ after TBS; $n=6$ in each group, $\mathrm{F}_{(3,15)}=0.71, p=0.56$ with $\mathrm{KO}+\mathrm{ACSF}$ group for comparison, one-way repeated measures ANOVA). Furthermore, these drugs did not affect the L-LTP in Fmr1 WT mice (MPEP: $139.6 \pm 2.3 \%$, SB415286: $134.7 \pm 9.8 \%$, CT99021: $139.2 \pm 11.6 \%$ of the baseline at $3 \mathrm{~h}$ after TBS; $n=6$ in each group, $\mathrm{F}_{(3,15)}=0.10, p=0.96$, one-way repeated measures ANOVA with WT + ACSF group for comparison; Figure $6 \mathrm{j}-\mathrm{m}$ ).

\section{Pharmaceutical Rescuing Effect of the Impaired Trace Fear Memory in Fmr1 KO Mice}

In our previous works, we already confirmed that Fmr1 KO mice have deficits in fear memory conditioning (Zhao et al, 2005a). To determine whether inhibition of the mGluR5 and GSK3 in the ACC can rescue the deficits in learning in the $\mathrm{KO}$ mice, we thus combined the microinjection of the MPEP, SB415286, or CT99021 with the trace fear conditioning paradigm. MPEP ( $5 \mathrm{nM}$, according to Perez de la Mora et al, 2006), SB415286 (10, 50, or $100 \mathrm{nM})$, or CT99021 (10, 50 , or $100 \mathrm{nM}$ ) were microinjected into both sides of the ACC $(0.5 \mu \mathrm{l}$ in each side) $30 \mathrm{~min}$ before trace fear conditioning and the freezing time in the training and testing periods were summarized (Supplementary Figures $2 \mathrm{a}$ and $\mathrm{b}$ and 3). Results showed that Fmr1 WT mice successfully learned the trace fear conditioning after $10 \mathrm{CS}-$ US pairings and showed significant freezing throughout the training session. However, the freezing time in Fmr1 KO mice was greatly decreased (WT: $1164.5 \pm 124.0 \mathrm{~s}, \mathrm{KO}$ : $233.5 \pm 45.8 \mathrm{~s}, n=15$ in WT and 14 in KO mice; $p<0.001$, unpaired $t$-test). Similarly, the freezing time in testing session was also decreased in $\mathrm{KO}$ mice when compared with WT mice (WT: $492.1 \pm 74.7 \mathrm{~s}$, KO: $44.2 \pm 8.5 \mathrm{~s} ; p<0.001$, unpaired $t$-test) (Supplementary Figure $2 \mathrm{~b}$ ). These results suggest that Fmr1 KO mice are deficient at acquiring trace fear memory during training, as well as in the expression of trace fear memory during testing on the following day. However, after MPEP ( $5 \mathrm{nM}, n=8$ ) microinjection into the ACC, the freezing time in Fmr1 KO mice was significantly increased, both in the training $(928.7 \pm 66.3 \mathrm{~s} ; p<0.001$ compared with $\mathrm{KO}$ mice with saline injection) and in the testing (381.4 $\pm 67.9 \mathrm{~s} ; p<0.001$ compared with $\mathrm{KO}$ mice with saline injection) sessions. After SB415286 was microinjected into the ACC, the freezing time in the training and testing session was rescued either. Microinjection of both 10 and $50 \mathrm{nM}$ SB415286 increased the freezing time in Fmr1 KO mice in the training $(10 \mathrm{nM}: 1155.7 \pm 234.6 \mathrm{~s}$, $n=7, p<0.001 ; 50 \mathrm{nM}: 1134.5 \pm 301.0 \mathrm{~s}, n=6, p<0.001)$ and in the testing $(10 \mathrm{nM}: 277.3 \pm 80.9 \mathrm{~s}, \quad p=0.009$; $50 \mathrm{nM}: 206.2 \pm 89.3 \mathrm{~s}, p=0.049)$ sessions. However, $100 \mathrm{nM}$
SB415286 had no effect on the freezing time in the training period $(372.1 \pm 185.8 \mathrm{~s}, \quad n=6, \quad p=0.34)$, and it even decreased the freezing time in the testing period $(7.9 \pm 3.0 \mathrm{~s}, p=0.049)$. Similar rescuing effect was observed after the microinjection of the GSK inhibitor CT99021 into the ACC. Microinjection of $10 \mathrm{nM} \mathrm{CT} 99021$ into the ACC of Fmr1 KO mice increased the freezing time in the training $(1357.7 \pm 285.0 \mathrm{~s}, n=6, p<0.001)$ and testing $(285.9 \pm 89.0 \mathrm{~s}$, $p=0.007$ ) sessions. Microinjection of 50 or $100 \mathrm{nM} \mathrm{CT}$ 99021 had no effect on the freezing time in both the training (50 nM: $513.5 \pm 152.4 \mathrm{~s}, n=6, p=0.11 ; 100 \mathrm{nM}: 195.4 \pm 98.8 \mathrm{~s}$, $n=6, p=0.88)$ and testing periods (50 nM: $198.7 \pm 111.1 \mathrm{~s}$, $p=0.06 ; \quad 100 \mathrm{nM}: 28.0 \pm 14.4 \mathrm{~s}, \quad p=0.83$ ) (Supplementary Figure $2 \mathrm{~b})$. The difference among $\mathrm{KO}+$ saline, $\mathrm{KO}+\mathrm{MPEP}$, $\mathrm{KO}+\mathrm{SB} 415286$, and $\mathrm{KO}+\mathrm{CT} 99021$ groups was measured by using one-way repeated measures ANOVA followed by Holm-Sidak post hoc test, with Fmr1 $\mathrm{KO}+$ saline as control $\left(\mathrm{F}_{(8,51)}=10.234 / 7.29\right.$ in training/testing session, $\left.p<0.001\right)$. In addition, MPEP (5 nM), SB415286 (10 nM), or CT99021 $(10 \mathrm{nM})$ microinjection into the ACC did not change the freezing time of Fmr1 WT mice in training (MPEP: $1117.7 \pm 151.5 \mathrm{~s}, \quad n=7 ; \quad$ SB415286: $1041.9 \pm 196.4 \mathrm{~s}, \quad n=8$; CT99021: $1407.0 \pm 219.7 \mathrm{~s}, n=6 ; \mathrm{F}_{(3,18)}=1.40, p=0.28$ in comparison with WT mice with saline injection; one-way repeated measures ANOVA) and testing sessions (MPEP: 433.1 \pm 61.4 s; SB415286: $304.8 \pm 51.6$ s; CT99021: $534.7 \pm$ $162.9 \mathrm{~s} ; \mathrm{F}_{(3,18)}=1.28, p=0.31$ in comparison with WT mice with saline injection; one-way repeated measures ANOVA). In control group (mice only received CS but not US), neither WT nor KO mice showed obvious freezing behaviors.

\section{Pharmaceutical Rescuing Effect of the Trace Fear Learning Induced AMPAR GluA1 Subunit Upregulation}

The rapid increase of membrane AMPA receptor GluA1 subunits within the ACC is critical for trace fear learning (Descalzi et al, 2012). As Fmr1 KO mice exhibited deficit in fear memory learning, we wanted to know whether the defective learning ability is due to the lack of upregulation of GluA1 within the ACC after trace fear training (Descalzi et al, 2012). Adult Fmr1 WT and KO mice with saline injection into the ACC were then exposed to trace fear conditioning and ACC was extracted for western blot analysis immediately after testing (Supplementary Figure 2c). In accordance with previous observations, Fmr1 WT mice exposed to trace fear conditioning exhibited more membrane GluA1 compared with WT mice in control group exposed to the CS only (control: $1.01 \pm 0.02$; trace fear: $1.67 \pm 0.09$ times the control value; $n=6$ in each group, $p<0.001$, unpaired $t$-test). In contrast, Fmr1 KO mice exposed to trace fear conditioning showed similar levels of membrane GluA1 as $\mathrm{KO}$ mice in control group exposed to the CS alone (control: $0.90 \pm 0.09$; trace fear: $0.86 \pm 0.09$; $n=6$ in each group, $p=0.73$, unpaired $t$-test). These results suggested that trace fear memory conditioning increase the membrane GluA1 expression in WT but not in Fmr1 KO mice. After ACC microinjection of MPEP ( $5 \mathrm{nM}$ ) or GSK inhibitor SB 415286 (10 nM), however, obvious increased membrane GluA1 was observed in Fmr1 KO mice with trace fear conditioning (KO + MPEP: $1.46 \pm 0.16$; $\mathrm{KO}+$ SB415286: $1.31 \pm 0.16 ; n=6$ in each group, $\mathrm{F}_{(2,10)}=26.8$, $\mathrm{p}<0.001$, one-way repeated measures ANOVA followed by 
Holm-Sidak post hoc test with Fmrl $\mathrm{KO}+$ saline in fear conditioning group as control). Meanwhile, MPEP and SB415286 did not change the membrane GluA1 expression in WT mice after trace fear conditioning (WT + saline: $1.67 \pm 0.09 ; \quad$ WT + MPEP: $1.61 \pm 0.17 ; \quad$ WT + SB415286: $1.57 \pm 0.13$. $n=6$ in each group, $\mathrm{F}_{(2,10)}=0.32, p=0.73$, one-way repeated measures ANOVA). The effect of another GSK inhibitor CT99021 on the expression of membrane GluA1 was also examined (Supplementary Figure 2d). Fmr1 WT and KO mice with saline or CT99021 microinjection into the ACC were exposed by CS-US pairing training and ACC was extracted for western blot analysis immediately after testing. We found that CT99021 injected into the ACC significantly increased the expression of membrane GluA1 compared with $\mathrm{KO}$ mice with saline injection after trace fear conditioning $\quad(\mathrm{KO}+\mathrm{CT} 99021: \quad 0.87 \pm 0.30, \mathrm{KO}+$ saline: $0.47 \pm 0.04, p<0.001$, unpaired $t$-test). CT99021 did not affect the expression of membrane GluA1 in WT mice after trace fear conditioning (WT + CT99021: $0.93 \pm 0.09, \mathrm{WT}+$ saline: $1.00 \pm 0.04, p=0.48$, unpaired $t$-test).

\section{DISCUSSION}

In the present study, we provide the first evidence, to our knowledge, that FMRP is critical for cortical L-LTP in the ACC. Our recent studies have consistently demonstrated that cingulate plasticity contributes to trace fear memory (Descalzi et al, 2012; Steenland et al, 2012; Wu et al, 2008; Zhao et al, 2005a). Loss of E-LTP in our previous report (Zhao et al, 2005a) and L-LTP in the present study provide synaptic basis explaining the behavioral defect of trace fear in Fmr1 KO mice. Furthermore, our study using 64-channel multielectrode recording system reveals two major findings. First, L-LTP does not occur in all active channels within the cortex. This also explains the finding that LTP cannot be induced at $100 \%$ by using traditional field potential recording system. In the case of failed LTP induction, we often propose that it is because of poor conditions of brain slices. However, the present results suggest that L-LTP may be pathway dependent. In fact, in several original LTP studies in the hippocampus, the failure of LTP induction has been reported (between 57.9 and $85.2 \%$ success rate) (Chavez-Noriega et al, 1990; Clark and Collingridge, 1995; Malinow and Tsien, 1990; Stelzer et al, 1994; Wheal et al, 1983). Second, we found that L-LTP induction triggered the recruitment of cortical circuit. Some of inactive channels showed active synaptic responses after L-LTP induction. These results suggest that L-LTP not only enhances existing synaptic responses (temporal plasticity), but also contributes to the expansion of the active cortical circuits (spatial plasticity) in the ACC. Our present studies provide a potential important cellular model for investigating the molecular mechanisms of cortical network recruitment in the future. Finally, we demonstrate that FMRP has critical roles in cortical network recruitment as well as the potentiation of synaptic responses.

\section{Technical Considerations of Recording L-LTP using a Multielectrode Array Recording System}

There are three obvious technical advantages of the multielectrode recording system. First, slices were placed on the surface of the recording chamber and both stimulation and recording electrodes were located below the brain slices. In a typical interface slice chamber (where L-LTP can be recorded), the accumulation of water drops along the glass (recording) and metal (stimulating) electrodes commonly causes problems. The falling of water drops to the stimulating or recording tips dramatically affects the recorded synaptic responses, especially during L-LTP studies. In this multielectrode recording system, we did not see such a problem. Thus, it is more efficient at obtaining stable and long-lasting synaptic responses. Second, the MED64 system allows us to monitor changes of field responses in different locations. This provides the chance to detect possible plastic changes in brain circuit within the ACC. Conventional recording system can only measure field responses from one or two locations (two pathways recording). Finally, for the study of the role of FMRP, the MED64 system can examine the contribution of FMRP in synaptic plasticity at circuit level using the same brain slices.

\section{Recruitment of Activated Channels after LTP Induction}

One interesting finding here is the recruitment of synaptic responses in the course of L-LTP induction. There are at least three possible explanations for the recruitment of responses. First, there is not enough glutamate release because of the low activity of presynaptic glutamate transporter or the improper behavior of vesicle docking and fusion. L-LTP may enhance the release of glutamate by modifying the presynaptic fusion pore or glutamate transporter or other unknown mechanisms (Choi et al, 2003; Errington et al, 2003). Consequently, active responses are recruited. Second, these recruited synapses are originally (before L-LTP induction) silent, and TBS induced the recruitment of functional AMPA receptors to the synaptic zone (Kerchner and Nicoll, 2008; Nicoll and Malenka, 1999; Shi et al, 2001). However, up to now, most of the reported silent synapses have only been observed in animals within two postnatal weeks (Isaac et al, 1997; Kerchner and Nicoll, 2008; Liao et al, 1995). However, some other results indicated that $\sim 17 \%$ synapses in the hippocampus CA1 of adult rats contained only NMDA receptors (Nusser et al, 1998), and similar results are also confirmed by other groups (He et al, 1998). Finally, the recruited responses can be because of postsynaptic trafficking of AMPA receptors after the L-LTP induction. Future studies are clearly needed to examine the synaptic mechanism for network recruitment after L-LTP in the ACC.

\section{Fmr1 KO Mice Exhibited Reduced L-LTP in the ACC}

FMRP is reported to repress translation of target mRNAs in dendritic spines. The loss of FMRP may cause overexpression of many proteins that are important for synaptic plasticity (Bhakar et al, 2012; Zalfa et al, 2003). Although it is consistently reported that LTD is exaggerated in hippocampus (Huber et al, 2002; Zhang et al, 2009) and cerebellum (Koekkoek et al, 2005), LTP impairment depends on the region of the brain as well as the induction protocols. Some reports find that LTP is not affected in the hippocampus (Bear et al, 2004; Godfraind et al, 1996; Paradee et al, 1999; Zhang et al, 2009), whereas others show 
that LTP is reduced in the hippocampus ( $\mathrm{Hu}$ et al, 2008; Larson et al, 2005; Lauterborn et al, 2007; Lee et al, 2011; Shang et al, 2009). In the ACC, we reported that the early phase of LTP was impaired in cingulate pyramidal cells (Zhao et al, 2005a). In the present study, we extended the work to L-LTP and found that both network L-LTP and recruitment of channel responses in the ACC of Fmr1 KO mice were greatly reduced in comparison with those in Fmr1 WT mice. However, the basal synaptic transmission efficiency (input-output) is not changed. Our results strongly suggest that cortical potentiation, both the earlyphase LTP (E-LTP) and L-LTP, is blocked in Fmrl KO mice.

\section{Pharmacological Inhibition of mGluR5 or GSK3 Rescued the Impaired L-LTP and Trace Fear Memory in Fmr1 KO Mice}

The role of mGluR5 in the hippocampus of Fmr1 KO mice has been well investigated. The evidence originally comes from that the mGluR5-dependent LTD is exaggerated in the hippocampus of Fmr1 KO mice (Huber et al, 2002). In contrast with FMRP that is a suppressor for dendritic protein synthesis, mGluR5 functions as an activator for the translation of new proteins related to synaptic plasticity (Comery et al, 1997; Huber et al, 2000; Weiler and Greenough, 1993). FMRP and mGluR5 thus might play opponent regulatory effects (Dolen and Bear, 2008), and FXS may be corrected by reducing the activity of mGluR5. In fact, pharmacological or genetic inhibition of mGluR5 can rescue many of the Fragile $\mathrm{X}$ phenotypes, such as the immature dendritic spine in the hippocampus, defective spatial memory and contextual fear memory (for review see Bhakar et al, 2012; Dolen and Bear, 2008). These findings indicate that mGluR5 antagonist might be a good candidate for therapeutic application. In addition, GSK3 is a newly found signal protein that is important for synaptic plasticity, closely related to mGluR5 signaling and overexpressed in Fmr1 KO mice (Bradley et al, 2012; Guo et al, 2012; Liu et al, 2005; Min et al, 2009). However, the function of GSK3 in FXS is less investigated. In the present study, we found that MPEP, SB415286, and CT99021 all rescued L-LTP when applied during the LTP induction. These results clearly showed that the exaggerated activities of mGluR5 and GSK may contribute to the impairment of the induction of L-LTP in the ACC. In contrast, we found that these activities are not required for the maintenance of L-LTP.

In consistence with the electrophysiological data, microinjection of MPEP, SB415286, or CT99021 at $30 \mathrm{~min}$ before CS-US paired training rescued the defective performance of Fmr1 KO mice in fear memory training and testing. As it is less possible that the inhibition effect from injected drugs could last for a long time, we suppose that the drugs play roles to rescue learning instead of memory ability. Western blotting results further showed that one of the possible mechanisms for the electrophysiological and behavioral rescuing effect comes from that mGluR5 antagonist and GSK inhibitors increased the expression of membrane GluA1 that is normally increased after LTP induction or injuries in WT animals (Descalzi et al, 2012; Zhuo, 2014). In our behavioral experiments, it is possible that the increased freezing performance also comes from the increased sensory sensitivity to shock or locomotor functions after drug application. However, we found no difference in the freezing time between Fmrl WT and KO mice in the first several trials during the CS-US training procedure, suggesting that the sensitivity to shock or motor function was not changed. However, we cannot rule out the possible influence of the drugs for the anxiety in these animals. Finally, we found that the rescuing effect of MPEP and GSK inhibitors is quite similar regardless of electrophysiological, behavioral, or biochemical phenotypes, suggesting that mGluR5 and GSK3 may link to each other. Previous studies found that MPEP inhibits GSK3 activity by increasing the inhibitory phosphorylation of GSK3 (Liu et al, 2005; Min et al, 2009; Yuskaitis et al, 2010), whereas combined inhibition of mGluR5 and GSK3 does not cause synergistic effect (Min et al, 2009). Therefore, it is likely that GSK3 is one of the downstream targets of mGluR5.

In summary, our results demonstrate that FMRP is critical for cortical L-LTP as well as the recruitment of cortical network. Pharmacological blockade of mGluR5 or GSK3 activation can rescue the L-LTP and network recruitment in the Fmrl KO mice. These new findings provide basic mechanisms for future treatment of cortexrelated cognitive defects in fragile $\mathrm{X}$ patients.

\section{FUNDING AND DISCLOSURE}

The authors declare no conflict of interest.

\section{ACKNOWLEDGEMENTS}

This work was supported by grants from the EJLB-CIHR Michael Smith Chair in Neurosciences and Mental Health, Canada Research Chair, Canadian Institute for Health Research operating Grants (MOP-124807), and NSERC Discovery Grant (RGPIN 402555) awarded to Min Zhuo; by the Major International Joint Research Project through National Science Foundation of China (31010103909) awarded to Min Zhuo and Yun-Qing Li; by the postdoctoral fellowships from Fragile X Research Foundation of Canada awarded to Tao Chen and Kohei Koga; and by the National Science Foundation of China (31371126) awarded to Tao Chen.

\section{Author Contributions}

Tao Chen, Yun-Qing Li, and Min Zhuo conceived and designed the overall study; Tao Chen, Qian Song, MingGang Liu, and Kohei Koga conducted the electrophysiological experiments; Jing-Shan $\mathrm{Lu}$ and Giannina Descalzi carried out western blot works; and Jing-Shan Lu and Qian Song provided the behavioral data. All authors were involved in data collection, analysis, and interpretation of the data. Tao Chen and Min Zhuo drafted the article. All authors revised the article and approved the final version.

\section{REFERENCES}

Abel T, Nguyen PV, Barad M, Deuel TA, Kandel ER, Bourtchouladze R (1997). Genetic demonstration of a role for PKA in the late phase of LTP and in hippocampus-based long-term memory. Cell 88: 615-626.

Auerbach BD, Bear MF (2010). Loss of the fragile X mental retardation protein decouples metabotropic glutamate receptor 
dependent priming of long-term potentiation from protein synthesis. J Neurophysiol 104: 1047-1051.

Bagni C, Greenough WT (2005). From mRNP trafficking to spine dysmorphogenesis: the roots of fragile $\mathrm{X}$ syndrome. Nat Rev Neurosci 6: 376-387.

Barco A, Alarcon JM, Kandel ER (2002). Expression of constitutively active CREB protein facilitates the late phase of long-term potentiation by enhancing synaptic capture. Cell 108: 689-703.

Bear MF, Huber KM, Warren ST (2004). The mGluR theory of fragile X mental retardation. Trends Neurosci 27: 370-377.

Berry-Kravis E, Sumis A, Hervey C, Nelson M, Porges SW, Weng N et al (2008). Open-label treatment trial of lithium to target the underlying defect in fragile X syndrome. J Dev Behav Pediatr 29: 293-302.

Bhakar AL, Dolen G, Bear MF (2012). The pathophysiology of fragile X (and what it teaches us about synapses). Annu Rev Neurosci 35: 417-443.

Bliss TV, Collingridge GL, Morris RG (2003). Introduction. Longterm potentiation and structure of the issue. Philos Trans $R$ Soc Lond B Biol Sci 358: 607-611.

Bliss TV, Cooke SF (2011). Long-term potentiation and long-term depression: a clinical perspective. Clinics (Sao Paulo) 66(Suppl 1): 3-17.

Bradley CA, Peineau S, Taghibiglou C, Nicolas CS, Whitcomb DJ, Bortolotto ZA et al (2012). A pivotal role of GSK-3 in synaptic plasticity. Front Mol Neurosci 5: 13.

Chavez-Noriega LE, Halliwell JV, Bliss TV (1990). A decrease in firing threshold observed after induction of the EPSP-spike (E-S) component of long-term potentiation in rat hippocampal slices. Exp Brain Res 79: 633-641.

Choi S, Klingauf J, Tsien RW (2003). Fusion pore modulation as a presynaptic mechanism contributing to expression of long-term potentiation. Philos Trans R Soc Lond B Biol Sci 358: 695-705.

Clark KA, Collingridge GL (1995). Synaptic potentiation of dualcomponent excitatory postsynaptic currents in the rat hippocampus. J Physiol 482(Pt 1): 39-52.

Comery TA, Harris JB, Willems PJ, Oostra BA, Irwin SA, Weiler IJ et al (1997). Abnormal dendritic spines in fragile X knockout mice: maturation and pruning deficits. Proc Natl Acad Sci USA 94: 5401-5404.

Descalzi G, Li XY, Chen T, Mercaldo V, Koga K, Zhuo M (2012). Rapid synaptic potentiation within the anterior cingulate cortex mediates trace fear learning. Mol Brain 5: 6.

Dolen G, Bear MF (2008). Role for metabotropic glutamate receptor 5 (mGluR5) in the pathogenesis of fragile $\mathrm{X}$ syndrome. J Physiol 586: 1503-1508.

Errington ML, Galley PT, Bliss TV (2003). Long-term potentiation in the dentate gyrus of the anaesthetized rat is accompanied by an increase in extracellular glutamate: real-time measurements using a novel dialysis electrode. Philos Trans R Soc Lond B Biol Sci 358: 675-687.

Frey U, Huang YY, Kandel ER (1993). Effects of cAMP simulate a late stage of LTP in hippocampal CA1 neurons. Science 260: 1661-1664.

Godfraind JM, Reyniers E, De Boulle K, D'Hooge R, De Deyn PP, Bakker CE et al (1996). Long-term potentiation in the hippocampus of fragile X knockout mice. Am J Med Genet 64: 246-251.

Guo W, Murthy AC, Zhang L, Johnson EB, Schaller EG, Allan AM et al (2012). Inhibition of GSK3beta improves hippocampusdependent learning and rescues neurogenesis in a mouse model of fragile X syndrome. Hum Mol Genet 21: 681-691.

He Y, Janssen WG, Morrison JH (1998). Synaptic coexistence of AMPA and NMDA receptors in the rat hippocampus: a postembedding immunogold study. J Neurosci Res 54: 444-449.

Hu H, Qin Y, Bochorishvili G, Zhu Y, van Aelst L, Zhu JJ (2008). Ras signaling mechanisms underlying impaired GluR1-dependent plasticity associated with fragile X syndrome. J Neurosci $\mathbf{2 8}$ 7847-7862.
Huber KM, Gallagher SM, Warren ST, Bear MF (2002). Altered synaptic plasticity in a mouse model of fragile $\mathrm{X}$ mental retardation. Proc Natl Acad Sci USA 99: 7746-7750.

Huber KM, Kayser MS, Bear MF (2000). Role for rapid dendritic protein synthesis in hippocampal mGluR-dependent long-term depression. Science 288: 1254-1257.

Isaac JT, Crair MC, Nicoll RA, Malenka RC (1997). Silent synapses during development of thalamocortical inputs. Neuron 18: 269-280.

Kandel ER (2001). The molecular biology of memory storage: a dialogue between genes and synapses. Science 294: 1030-1038.

Kandel ER (2009). The biology of memory: a forty-year perspective. J Neurosci 29: 12748-12756.

Kang SJ, Liu MG, Chen T, Ko HG, Baek GC, Lee HR et al (2012). Plasticity of metabotropic glutamate receptor-dependent longterm depression in the anterior cingulate cortex after amputation. J Neurosci 32: 11318-11329.

Kerchner GA, Nicoll RA (2008). Silent synapses and the emergence of a postsynaptic mechanism for LTP. Nat Rev Neurosci 9: 813-825.

Koekkoek SK, Yamaguchi K, Milojkovic BA, Dortland BR, Ruigrok TJ, Maex R et al (2005). Deletion of FMR1 in Purkinje cells enhances parallel fiber LTD, enlarges spines, and attenuates cerebellar eyelid conditioning in Fragile X syndrome. Neuron 47: 339-352.

Larson J, Jessen RE, Kim D, Fine AK, du Hoffmann J (2005). Agedependent and selective impairment of long-term potentiation in the anterior piriform cortex of mice lacking the fragile $\mathrm{X}$ mental retardation protein. J Neurosci 25: 9460-9469.

Lauterborn JC, Rex CS, Kramar E, Chen LY, Pandyarajan V, Lynch $\mathrm{G}$ et al (2007). Brain-derived neurotrophic factor rescues synaptic plasticity in a mouse model of fragile $\mathrm{X}$ syndrome. J Neurosci 27: 10685-10694.

Lee HY, Ge WP, Huang W, He Y, Wang GX, Rowson-Baldwin A et al (2011). Bidirectional regulation of dendritic voltage-gated potassium channels by the fragile $\mathrm{X}$ mental retardation protein. Neuron 72: 630-642.

Li J, Pelletier MR, Perez Velazquez JL, Carlen PL (2002). Reduced cortical synaptic plasticity and GluR1 expression associated with fragile X mental retardation protein deficiency. Mol Cell Neurosci 19: 138-151.

Liao D, Hessler NA, Malinow R (1995). Activation of postsynaptically silent synapses during pairing-induced LTP in CA1 region of hippocampal slice. Nature 375: 400-404.

Liauw J, Wu LJ, Zhuo M (2005). Calcium-stimulated adenylyl cyclases required for long-term potentiation in the anterior cingulate cortex. J Neurophysiol 94: 878-882.

Liu F, Gong X, Zhang G, Marquis K, Reinhart P, Andree TH (2005). The inhibition of glycogen synthase kinase 3 beta by a metabotropic glutamate receptor 5 mediated pathway confers neuroprotection to Abeta peptides. J Neurochem 95: 1363-1372.

Liu MG, Kang SJ, Shi TY, Koga K, Zhang MM, Collingridge GL et al (2013). Long-term potentiation of synaptic transmission in the adult mouse insular cortex: multielectrode array recordings. J Neurophysiol 110: 505-521.

Malinow R, Tsien RW (1990). Presynaptic enhancement shown by whole-cell recordings of long-term potentiation in hippocampal slices. Nature 346: 177-180.

Meredith RM, Holmgren CD, Weidum M, Burnashev N, Mansvelder HD (2007). Increased threshold for spike-timingdependent plasticity is caused by unreliable calcium signaling in mice lacking fragile X gene FMR1. Neuron 54: 627-638.

Min WW, Yuskaitis CJ, Yan Q, Sikorski C, Chen S, Jope RS et al (2009). Elevated glycogen synthase kinase-3 activity in Fragile X mice: key metabolic regulator with evidence for treatment potential. Neuropharmacology 56: 463-472.

Neves G, Cooke SF, Bliss TV (2008). Synaptic plasticity, memory and the hippocampus: a neural network approach to causality. Nat Rev Neurosci 9: 65-75. 
Nicoll RA, Malenka RC (1999). Expression mechanisms underlying NMDA receptor-dependent long-term potentiation. Ann $N Y$ Acad Sci 868: 515-525.

Nusser Z, Lujan R, Laube G, Roberts JD, Molnar E, Somogyi P (1998). Cell type and pathway dependence of synaptic AMPA receptor number and variability in the hippocampus. Neuron 21: 545-559.

O'Donnell WT, Warren ST (2002). A decade of molecular studies of fragile X syndrome. Annu Rev Neurosci 25: 315-338.

Paradee W, Melikian HE, Rasmussen DL, Kenneson A, Conn PJ, Warren ST (1999). Fragile X mouse: strain effects of knockout phenotype and evidence suggesting deficient amygdala function. Neuroscience 94: 185-192.

Park S, Park JM, Kim S, Kim JA, Shepherd JD, Smith-Hicks CL et al (2008). Elongation factor 2 and fragile X mental retardation protein control the dynamic translation of Arc/Arg3.1 essential for mGluR-LTD. Neuron 59: 70-83.

Paxinos G, Franklin KBJ (2001). The Mouse Brain in Stereotaxic Coordinates. Academic Press: San Diego, CA.

Perez de la Mora M, Lara-Garcia D, Jacobsen KX, Vazquez-Garcia M, Crespo-Ramirez M, Flores-Gracia C et al (2006). Anxiolyticlike effects of the selective metabotropic glutamate receptor 5 antagonist MPEP after its intra-amygdaloid microinjection in three different non-conditioned rat models of anxiety. Eur $J$ Neurosci 23: 2749-2759.

Shang Y, Wang H, Mercaldo V, Li X, Chen T, Zhuo M (2009). Fragile $\mathrm{X}$ mental retardation protein is required for chemicallyinduced long-term potentiation of the hippocampus in adult mice. J Neurochem 111: 635-646.

Shi S, Hayashi Y, Esteban JA, Malinow R (2001). Subunit-specific rules governing AMPA receptor trafficking to synapses in hippocampal pyramidal neurons. Cell 105: 331-343.

Steenland HW, Li XY, Zhuo M (2012). Predicting aversive events and terminating fear in the mouse anterior cingulate cortex during trace fear conditioning. J Neurosci 32: 1082-1095.

Stelzer A, Simon G, Kovacs G, Rai R (1994). Synaptic disinhibition during maintenance of long-term potentiation in the CA1 hippocampal subfield. Proc Natl Acad Sci USA 91: 3058-3062.

Toyoda H, Zhao MG, Mercaldo V, Chen T, Descalzi G, Kida S et al (2010). Calcium/calmodulin-dependent kinase IV contributes to translation-dependent early synaptic potentiation in the anterior cingulate cortex of adult mice. Mol Brain 3: 27.

Wang H, Gong B, Vadakkan KI, Toyoda H, Kaang BK, Zhuo M (2007). Genetic evidence for adenylyl cyclase 1 as a target for preventing neuronal excitotoxicity mediated by N-methyl-Daspartate receptors. J Biol Chem 282: 1507-1517.
Waung MW, Pfeiffer BE, Nosyreva ED, Ronesi JA, Huber KM (2008). Rapid translation of Arc/Arg3.1 selectively mediates mGluR-dependent LTD through persistent increases in AMPAR endocytosis rate. Neuron 59: 84-97.

Weiler IJ, Greenough WT (1993). Metabotropic glutamate receptors trigger postsynaptic protein synthesis. Proc Natl Acad Sci USA 90: 7168-7171.

Wheal HV, Lancaster B, Bliss TV (1983). Long-term potentiation in Schaffer collateral and commissural systems of the hippocampus: in vitro study in rats pretreated with kainic acid. Brain Res 272: $247-253$

Wilson BM, Cox CL (2007). Absence of metabotropic glutamate receptor-mediated plasticity in the neocortex of fragile $\mathrm{X}$ mice. Proc Natl Acad Sci USA 104: 2454-2459.

Wu LJ, Li X, Chen T, Ren M, Zhuo M (2009). Characterization of intracortical synaptic connections in the mouse anterior cingulate cortex using dual patch clamp recording. Mol Brain 2: 32 .

Wu LJ, Zhang XH, Fukushima H, Zhang F, Wang H, Toyoda H et al (2008). Genetic enhancement of trace fear memory and cingulate potentiation in mice overexpressing $\mathrm{Ca} 2+1$ calmodulin-dependent protein kinase IV. Eur J Neurosci 27: 1923-1932.

Yuskaitis CJ, Mines MA, King MK, Sweatt JD, Miller CA, Jope RS (2010). Lithium ameliorates altered glycogen synthase kinase-3 and behavior in a mouse model of fragile X syndrome. Biochem Pharmacol 79: 632-646.

Zalfa F, Giorgi M, Primerano B, Moro A, Di Penta A, Reis S et al (2003). The fragile $X$ syndrome protein FMRP associates with BC1 RNA and regulates the translation of specific mRNAs at synapses. Cell 112: 317-327.

Zhang J, Hou L, Klann E, Nelson DL (2009). Altered hippocampal synaptic plasticity in the FMR1 gene family knockout mouse models. J Neurophysiol 101: 2572-2580.

Zhao MG, Toyoda H, Ko SW, Ding HK, Wu LJ, Zhuo M (2005a). Deficits in trace fear memory and long-term potentiation in a mouse model for fragile X syndrome. J Neurosci 25: 7385-7392.

Zhao MG, Toyoda H, Lee YS, Wu LJ, Ko SW, Zhang XH et al (2005b). Roles of NMDA NR2B subtype receptor in prefrontal long-term potentiation and contextual fear memory. Neuron 47: 859-872.

Zhuo M (2014). Long-term potentiation in the anterior cingulate cortex and chronic pain. Philos Trans R Soc Lond B Biol Sci 369: 20130146.

Supplementary Information accompanies the paper on the Neuropsychopharmacology website (http://www.nature.com/npp) 